This article has been accepted for publication in the Journal of Medical Ethics, April 2020 following peer review, and the Version of Record can be accessed online at http://dx.doi.org/10.1136/medethics-2019105762

\title{
Considering Medical Assistance in Dying for Minors: The Complexities of Children's Voices
}

\section{Harprit Kaur Singh ${ }^{1}$, Mary Ellen Macdonald ${ }^{2}$, Franco A. Carnevale ${ }^{3}$}

1. Toronto, ON. Canada.

2. Faculty of Dentistry, McGill University. Montreal, QC. Canada.

3. Ingram School of Nursing, McGill University. Montreal, QC. Canada.

Keywords: children, death, euthanasia, law 


\section{STATEMENTS:}

Funding: This output draws on research supported by the Social Sciences and Humanities Research Council.

I*I
Conseil de recherches en sciences humaines du Canada

\section{Canadä}

Acknowledgements: This manuscript builds on the Master's work of the first author, completed at McGill University (Montreal, QC, Canada) in 2017-18, about considering an extension of MAID legislation to minors in Canada. The Master's work on which this manuscript is based was presented at the Canadian Bioethics Society Conference 2018 (Halifax, NS, Canada). We would like to acknowledge Dr. Natalie Stoljar, Associate Professor, Department of Philosophy, McGill University for her contributions to the design and critical review of the content of this manuscript as a co-supervisor of the first author's Master's work. We would like to acknowledge the VOICE team at McGill University, (Montreal, QC., Canada), and the Macdonald Lab at McGill University (Montreal, QC., Canada) for providing thoughtful, critical feedback on the content of this manuscript. Thank you to Dr. Gail Teachman (Assistant Professor, School of Occupational Therapy, University of Western Ontario) for sharing knowledge which informed the content of this manuscript.

Contributorship Statement: Conception and design of this work was done by the first and second authors. Both the second and third author have revised this work critically for important intellectual content. The first author conducted the literature search, drafted this work and revised it based on feedback provided by co-authors and collaborators. The first author is the guarantor of this work. This manuscript has been read and approved by all authors.

License Statement: I, the Submitting Author has the right to grant and does grant on behalf of all authors of the Work (as defined in the below author licence), an exclusive licence and/or a non-exclusive licence for contributions from authors who are: i) UK Crown employees; ii) where BMJ has agreed a CC-BY licence shall apply, and/or iii) in accordance with the terms applicable for US Federal Government officers or employees acting as part of their official duties; on a worldwide, perpetual, irrevocable, royalty-free basis to BMJ Publishing Group Ltd ("BMJ") its licensees and where the relevant Journal is co-owned by BMJ to the co-owners of the Journal, to publish the Work in Journal of Medical Ethics and any other BMJ products and to exploit all rights, as set out in our licence. 


\begin{abstract}
Medical assistance in dying (MAID) legislation in Canada followed much deliberation after the Supreme Court of Canada's ruling in Carter v. Canada. Included in this deliberation was the Special Joint Committee on Physician Assisted Dying's recommendation to extend MAID legislation beyond the inclusion of adults to mature minors. Children's agency is a construct advanced within childhood studies literature which entails eliciting children's voices in order to recognize children as active participants in constructing their own childhoods. Using this framework, we consider the possible extension of MAID legislation to most minors. We highlight important questions regarding how insights from children's voices could be mobilized in the life or death context of MAID. We conclude that children's voices have the potential to help determine their eligibility for MAID; however, incorporating children's voices in the context of MAID requires careful consideration due to the complexity of voice.
\end{abstract}

\title{
Introduction
}

In February 2015, the Supreme Court of Canada made its final ruling in the Carter v. Canada ${ }^{1}$ legal case, indicating that the prohibition of medical assistance in dying (MAID) in Canada, as per sections 14 and 241b of the Criminal Code of Canada, was against the Canadian Charter of Rights and Freedoms ${ }^{2}$. The Supreme Court ruled that the prohibition of MAID was a violation of section one of the Charter, as well as section seven, the right to life, liberty, and security $^{2}$. The Supreme Court gave the federal government twelve months to respond to their ruling with legislation, later extending this period by four months ${ }^{2}$.

In considering this ruling, the Canadian government formed a number of working groups to determine how best to create MAID legislation in line with the Canadian Charter of Rights and Freedoms ${ }^{2}$. These working groups included the Expert Panel on Options for a Legislative 
Response to Carter, the Provincial-Territorial Expert Advisory Group on Physician Assisted Dying, and the Special Joint Committee on Physician Assisted Dying².

The Special Joint Committee on Physician Assisted Dying (hereafter referred to as 'the Special Joint Committee') included Senators and Members of Parliament who consulted with experts in multiple fields in order to outline a legislative framework for MAID ${ }^{2}$. Their report consisted of twenty-one recommendations for the future legislation ${ }^{3}$.

The deliberations of the various working groups, including the Special Joint Committee, helped inform MAID legislation (Bill C-14), which was finally passed in $2016^{2}$. According to the current legislation, in order to be eligible for MAID, patients must be adults (ages eighteen and over), be eligible for provincial health care coverage, be mentally competent (i.e., able to understand and reasonably evaluate information), provide voluntary and informed consent, and have a grievous and irremediable condition ${ }^{2}$. The presence of a grievous and irremediable condition is defined as: the presence of enduring, intolerable physical or psychological suffering; having a serious illness, disease, or disability; being in an advanced state of irreversible decline; and it being the case that one's natural death is reasonably foreseeable ${ }^{2}$.

MAID legislation is currently limited to adults. One recommendation in the Special Joint Committee's report was to extend this legislation to include mature minors (i.e., children assessed as having the capacity to consent to or decline medical interventions ${ }^{4}$ ) no later than three years after legislation has been enacted ${ }^{3}$.

The recommendation states,

That the Government of Canada implement a two-stage legislative process, with the first stage applying immediately to competent adult persons 18 years or older, to be followed by a second stage applying to competent mature minors, coming into force at a date no later than three years after the first stage has come into force ${ }^{3(\text { pp. } 21)}$. 
In December 2016, the Government of Canada commissioned the Council of Canadian Academies to conduct an independent review of evidence that could inform decision making regarding MAID for mature minors in Canada ${ }^{5}$ The Council of Canadian Academies released a report of their assessment in December $2018^{6}$.

Key concepts: Autonomy, Capacity, Mature Minors

Current eligibility criteria for MAID require that individuals have the capacity to consent to $\mathrm{MAID}^{2}$. Conventional understandings of capacity to consent to medical interventions such as MAID mobilize individualistic conceptions of autonomy. Autonomous individuals are adults who are considered to have sufficient capacity to make independent, voluntary and informed decisions regarding their health and medical care ${ }^{7}$. The term 'capacity' refers to an individual's cognitive ability to understand, appreciate and reason with the information they are provided, and to make rational decisions based on that information ${ }^{8}$. In the Canadian context, capacity for consent is assessed by health care providers ${ }^{9,10}$. In general, children are not considered 'autonomous'; therefore, they do not, by definition, have capacity to consent ${ }^{11}$.

The mature minor doctrine is a common law doctrine recognized in many Canadian jurisdictions; an exception is Quebec which is governed by a civil code ${ }^{12}$. A child is considered a mature minor if they demonstrate mature (i.e., adult-like) understanding of their medical condition, treatment options, related risks and benefits, and are able to appreciate and reason with this information to make their own medical decisions ${ }^{13}$ If a child is recognized as a mature minor, they can make certain medical decisions for themselves ${ }^{14}$.

\section{Children's Agency Framework}

The concept of children's agency has been promoted largely by the New Sociology of Childhood literature, pioneered in the early 1970 's ${ }^{15}$. Recognition of children's agency followed a 
shift in Western thought towards viewing children as persons rather than as the property of their parents or guardians ${ }^{15}$. Children's agency moves away from defining children only as "becomings"16(pp.303) - that is, thinking of children as valuable because they are 'becoming' adults - to also considering children as "beings"16(pp.303) - that is, valued as ends in themselves ${ }^{17}$.

Conventional autonomy frameworks cast children primarily as future adults ${ }^{18}$, rather than acknowledging that children are persons with morally meaningful perspectives on the world ${ }^{19}$. By viewing children as incomplete versions of adults, mainstream conceptions of autonomy can lead to morally objectifying children ${ }^{19}$. Moral objectification means denying recognition of children as active agents with morally meaningful subjectivities, instead treating them as depersonalized, 'moral objects' whose perspectives do not need to be taken into account ${ }^{20}$. This moral objectification is ethically problematic because children are persons ${ }^{\mathrm{i}}$, meaning they have moral status ${ }^{21}$. Moral status is a concept that identifies those individuals towards whom other persons have moral obligations ${ }^{21}$ such as respecting their agency and taking their experiences and feelings into account ${ }^{20}$. Treating children as objects and denying their subjectivity are violations of moral duties required to respect the moral status accorded to all persons.

Our argument thus far is that while children are not legally autonomous subjects, they still have agency ${ }^{18,22}$. Montreuil and Carnevale's concept analysis on agency defines it as "the capacity to act deliberately, speak for oneself, and reflect on the social worlds that shape their lives and the lives of others"23(pp.510). To say that a child has agency is not the same as recognizing a child as having autonomy ${ }^{24}$. Rather, recognizing children as agents means thinking

\footnotetext{
i 'Person' is a philosophical term according strong moral status ${ }^{20}$. There is no consensus in the literature regarding
} the specific characteristics required to be recognized as a person, which include, but are not limited to, the ability to have conscious experience, actual or potential moral agency, and the capacity for reason and self-awareness ${ }^{20}$. 
of them as having their own meaningful perspectives of the world and what matters to them ${ }^{25}$. For example, in a study of the moral experiences of children living at home with assisted ventilation, several children described their lives and assisted ventilation technology as good; as assistive, not burdensome, despite societal beliefs to the contrary ${ }^{26}$. Young children acknowledged that the technologies improved their lives and helped them participate in activities like other non-disabled children ${ }^{26}$. These children were able to demonstrate reflections on their views on good and bad, and right and wrong, and express morally meaningful preferences on how they should be treated ${ }^{26}$. To say that children have agency means acknowledging that they can make judgments and engage in reasoning more than adults think they can, even though these judgements and reasoning skills may not conform to adult-centered conceptions of autonomy ${ }^{22}$. Children's agential capacities are not less worthy of being recognized than adults' autonomous capacities $^{27}$.

\section{The Construct of Voice}

Valuing children's perspectives entails eliciting, listening and paying attention to these perspectives ${ }^{15}$. Voice is a construct that operationalizes access to a person's perspective. In practice, children's voices are communications in any form (i.e., verbal, written, illustrations, actions, using an assistive communication device, and/or silence). Silence is also a part of voice. Silence can be mistaken as a non-response; however, when considered within the context in which it occurs, silence can also convey meaning ${ }^{28,29}$. Children's voices include the communications of children who communicate differently, such as those who may rely on assistive communicative devices ${ }^{30}$. Ill children may have a limited ability to communicate verbally, either as a result of their illness, or due to a medical procedure (i.e., tracheostomy, mechanical ventilator). The childhood studies literature is mixed in its use of the phrases 
'children's voices' and 'child's voice'. We specifically use the phrase 'children's voices' to acknowledge that all children do not have a single, unified voice. Rather, each child is unique and has their own voice ${ }^{31}$.

\section{Reasons for using a Children's Agency Framework}

What are the reasons for using a children's agency framework to think about MAID for minors? Individualistic autonomy discourses, currently conventional in healthcare, exclude children by virtue of children being non-adults (i.e., non-autonomous decision-makers). In so doing, they morally objectify children by discounting the value of their voices, disregarding their perspectives, and reducing the expressions of children to demonstrations of immaturity ${ }^{19}$. This failure to treat children as persons thereby risks moral objectification ${ }^{19}$. An example comes from research conducted by Carter who provides the following excerpt from the diary of a child with chronic abdominal pain:

I've had pain in my stomach for nearly two years...one doctor told me that what she was seeing on examination and what she was being told were two different things. I was 11 and knew that I was being accused of lying. This made me really angry, because it didn't help the pain (it actually got worse) and it really hurt me to be called a liar when the pain was very real ${ }^{32(p p .34)}$.

Children's agency frameworks can help prevent moral objectification by recognizing children as active agents ${ }^{18}$ - as moral subjects - and emphasizing the importance of promoting children's participation in discussions and decisions pertaining to matters that affect them ${ }^{15}$.

Another consideration in support of the children's agency framework is the special privilege that is accorded to first-person accounts of mental states. Generally, unless you know someone very well and have reason to believe that they are lying, you accept what they say about themselves as true ${ }^{33}$. This is because people have a special (not absolute) kind of authority with respect to what they say about their own mental states, called first-person authority ${ }^{34}$. First- 
person accounts are treated with a presumption of truthfulness or reliability whereas third-person accounts are not ${ }^{34}$. This concept need not be applicable only to adults. Young children (beginning as young as 5-6 years-old) demonstrate an ability to recognize themselves as the authority on self-knowledge, especially for knowledge that has not been disclosed to others in order for them to know about $\mathrm{it}^{35,36}$. As the authority on self-knowledge, children's first-person avowals about their mental states have an "intrinsic credibility"37(pp.70) that third-person accounts of the same do not ${ }^{37}$. Further, adults (clinicians and parents/guardians) often dominate conversation in clinical encounters about children's health, especially when younger children are involved $^{38}$. Parents or guardians of terminally ill children who are at the end of life may have acute insight into their child's feelings, thoughts, and desires; however, they may rely on indirect measures to, and have difficulty with, gaining insight into their child's perspective ${ }^{39}$. Parents' accounts of their child's pain and suffering can also reflect their own conceptions of suffering and hopelessness ${ }^{40}$. The combination of these considerations and the concept of first person authority, suggest that more focus on children's own accounts - their first person avowals - of, for example, their feelings, thoughts and suffering in illness, is necessary to understand their experiences and perspective. Input from parents/guardians and healthcare providers can supplement these first-person avowals. .

\section{Medical Assistance in Dying (MAID) for Minors}

This manuscript builds upon the Master's work of the first author ${ }^{41}$, considering an extension of MAID legislation to minors in Canada. Using children's agency as a framework, we build our argument in two steps. First, we discuss expanding the scope of the proposed MAID legislation extension beyond mature minors to consider most children. Second, we explore the 
necessity and complexity of eliciting a child's own perspective in MAID deliberations, with particular concern for the eligibility criterion of intolerable suffering.

\section{Applying a Children's Agency Framework to MAID}

The recommendation by the Special Joint Committee to extend MAID legislation to minors refers specifically to mature minors ${ }^{3}$, which is a designation given to some children in accordance with the previously described mature minor doctrine. Even though mature minor designation is open to all children regardless of age ${ }^{14}$, adolescents are more likely to be recognized as mature minors than younger children. The favouring of adolescents in the mature minor doctrine is signaled in the Canadian Pediatric Society's definition of mature minors: "Mature minors are adolescents who have demonstrated decision-making abilities..."11(pp.139). Thus, the recommendation of the Special Joint Committee to extend MAID legislation to mature minors may foreclose on the inclusion of children younger than adolescence. Failure to meaningfully acknowledge the perspectives of younger children by excluding them from MAID is to risk morally objectifying them ${ }^{19}$. Applying a children's agency framework, we suggest moving beyond the mature minor limit on the Special Joint Committee's recommendation to consider a possible extension of MAID legislation to young people more broadly. The rest of this paper focuses on this broader consideration of extending MAID legislation to most minors in Canada.

We recognize that there is potential for debate on the ability to elicit and pay attention to the perspectives of some younger children, such as infants. The literature contains some examples of agency being demonstrated by infants ${ }^{42,43,44}$. Agency frameworks do not place any age or functional capacity limits on agency; however, there is uncertainty about how to understand agency in younger children due to a lack of sufficient knowledge or research on this 
topic $^{44,45}$. Further, the inclusion of individuals with mental health and/or intellectual or developmental disorders is subject to ongoing discussions in Canada, and these discussions are focused primarily on adults at this time ${ }^{46}$. The agential perspectives of children who communicate differently and/or with difficulty would need to be sought through alternative forms of communication and by working with parents as interpretive interlocutors; however, we recognize that there may be limitations to this in some cases, such as children with severe autism.

\section{Children's Voices in the Context of MAID.}

In regards to the previous discussion of first person authority, children's voices may play an important role in the context of MAID for minors by providing insight into the degree and extent of the suffering experience of the child. This insight can help determine whether the child is suffering intolerably, thus meeting a key eligibility criterion for MAID.

Intolerable suffering carries significant moral weight in justifying MAID ${ }^{47}$, as evidenced in the Supreme Court of Canada's ruling in Carter and the Special Joint Committee report ${ }^{3}$. The moral argument behind allowing MAID for mature minors is based on the cruelty of forcing any person, regardless of age, to continue to suffer intolerably until their natural death occurs ${ }^{48}$.

The experience of suffering and its intolerability entails subjectivity ${ }^{41}$. Intuitively, the best person to describe an experience that is subjective is the person themselves. As such, a child would have first-person authority with respect to accounts of their own suffering. If this special privilege is attributed to a child's own account of their suffering, then it is necessary to elicit children's voices to understand their suffering experiences and determine their eligibility for MAID.

\section{Complexity of 'Voice'}


We have identified two different reasons for recognizing children's voices within the context of MAID. However, one must be careful when recognizing voice in this context because voice is not an independent, authentic entity that can be narrowly attributed to a single person $^{30,49,50,51}$. Further, whereas children's voices will provide valuable and meaningful insight regarding the degree and extent of their suffering, that insight may not be straightforward to acquire $^{52}$ and cannot be the complete picture. This lack of a straightforward and complete understanding exists because voice - a child's or an adult's - is always mediated ${ }^{51,52}$ and multilayered ${ }^{50}$.

Following Russian philosopher and literary theorist, Bakhtin, voice is co-constructed and situated within the context of dialogue ${ }^{30}$. Imagine, for example, that you are engaging in dialogue with a close friend. The meaning of what you express to your friend in this dialogue is subject to interpretation by your friend. Similarly, you interpret what your friend means based on the words and gestures they use. Your friend responds to you based on their interpretation of the meaning behind your words and gestures. If you feel that your friend has misinterpreted what you were trying to convey, you can attempt to correct their understanding, perhaps by restating or providing an example. In this way, you and your friend engage in a back-and-forth dialogue, working together to co-construct the meanings behind what each of you has expressed. This coconstructed meaning is a Bakhtinian understanding of 'voice ${ }^{130}$. Voice is embedded within this back-and-forth process of interpretation ${ }^{29}$; therefore, it is always mediated ${ }^{51}$.

Children (like many adults) are deeply embedded in social contexts (e.g., family, friends, school) ${ }^{53}$. Children are reliant on the networks within these social contexts to meet their daily needs in order to survive ${ }^{17}$, and to navigate contexts such as the health care system. This social embeddedness is important to acknowledge for adequately recognizing both the contextual and 
relational nature of their voices. This context-dependent nature of children's voices is explained by Spyrou in his comments on his research on Greek-Cypriot children's constructions of national identities $^{50}$. Children's expressions of their national identities varied with respect to context ${ }^{50}$. For example, when the children were constructing their identities in their neighbourhood, they drew on the local culture to do so, which could be seen, for example, in the themes of their games and their choice of language ${ }^{50}$. When the children were constructing their identities within the school context, they expressed their identities in a more politically correct and nationalistic voice $^{50}$.

Much like relational conceptions of autonomy ${ }^{54,55}$, children's perspectives are influenced by the experiences and perspectives of others in their social contexts ${ }^{53}$. For example, the family is a social context in which there can be significant interrelation between the beliefs and values of parents and their children, and family members influence each other's outlook, while also allowing for each individual member to have their own beliefs, values, and ways of thinking ${ }^{56}$. Although children are agents, they are relationally embedded, adding an additional layer of complexity to understanding children's voices ${ }^{56}$.

Voice can be ambiguous and is multi-layered ${ }^{50}$. Spyrou's research demonstrates this multi-layered nature of voice, and how the deeper layers of meaning in children's voices can be uncovered $^{50}$. In an initial interview with Greek-Cypriot children, Spyrou asked the children about their views on Turks and the situation in Cyprus ${ }^{50}$. Most Greek-Cypriot children participating in the interview(s) described the Turks as evil and invaders ${ }^{50}$. Follow up interviews by Spyrou with the Greek-Cypriot children revealed that they were not referring to all Turks, but only to specific groups of Turks, such as those in government ${ }^{50}$. These follow up interviews are not an indication that the children were lying in the initial interview, or that their responses had been inauthentic ${ }^{50}$. 
Rather, a deeper layer of meaning behind the children's voices, and consequently a deeper understanding of their perspectives on the Turks, was revealed in the follow up interviews ${ }^{50}$. Spyrou's work demonstrates that voice can be ambiguous and difficult to unravel, and this possible ambiguity is a challenge that must be worked through ${ }^{50}$.

\section{Reflections on Extending MAID to Minors}

Due to the complexity of the construct of voice, policy-makers should proceed with caution when considering an extension of MAID legislation to minors, by taking time to carefully deliberate questions about when and how to give weight to children's perspectives within the context of MAID. Health care professionals are already being approached about MAID by the parents or guardians of children, many of whom would not meet the adult-centered requirements of capacity to be considered mature minors ${ }^{57}$. Just as the prohibition of assisted dying under the Criminal Code of Canada was challenged on the basis of Charter rights in Carter, parents or guardians may challenge the ineligibility of their children for MAID on the grounds of section seven of the Charter, the right to life, liberty, and security ${ }^{57}$. In the context of MAID, section seven of the Charter pertains to the protected right of each Canadian to waive their right to life, and the right to freedom from the threat of physical and psychological suffering - as a result of not having access to MAID ${ }^{1,58(s 7(2)(i i i))}$.

Insight into a child's illness and suffering experience, as acquired by paying attention to children's voices, could be a strong consideration in decision making about MAID for a minor, given how central the concept of intolerable suffering has been in justifying MAID legislation in

Canada. We believe that children's voices should compel conversations pertaining to MAID for a minor among children, parents/guardians, and health care providers. For example, if a child expresses the extent of their suffering to a parent or guardian, this could motivate a dialogue 
about MAID among the child, the parents/guardians, and healthcare providers. Alternatively, the parent or guardian may be the first to think about MAID for the minor and should work with healthcare providers to elicit children's voices in a dialogue about MAID. By providing information about the presence of intolerable suffering (or lack thereof) in a child, the insight provided by children's voices can help determine whether the child is eligible for MAID.

The complexity of voice has significant implications for eliciting children's voices in the context of MAID for minors. Voice is embedded within a process of multilayer avowal and interpretation $^{30,50}$. Therefore, eliciting children's voices may not result in a clear understanding of a child's suffering experience. Nonetheless, eliciting children's voices still holds the potential for providing invaluable insight into a child's experiences and their perspective on those experiences. In the case of MAID for minors, it is important to consider whether an uncertain picture of a child's suffering and illness experience, as acquired by paying attention to children's voices, would be sufficient to determine whether a minor is eligible for MAID.

By questioning the sufficiency of the knowledge that may be acquired from eliciting children's voices in the context of MAID, we are not suggesting that children's voices should not be elicited, nor that they must prove worthy of consideration. To abandon the elicitation and acknowledgement of children's voices would be a moral harm because it would entail failing to recognize children as persons with their own perspectives that are inherently worthy of consideration $^{19}$. By asking whether the understanding of a child's suffering experience derived from their voice would be enough, we are questioning the specific epistemological role that children's voices play within the context of MAID. Whereas children's voices can provide meaningful insight into a child's perspective and experience that could not likewise be acquired 
from third-person accounts, it is uncertain whether this meaningful insight would be ethically and legally sufficient when making a life or death decision such as MAID for a minor.

Would it ever be ethically acceptable to rely on the uncertainty that can exist from information derived through children's voices in such a high stakes decision? The presence of uncertainty means that some degree of risk of false determinations regarding the presence of intolerable suffering continues to exist. The presence of this risk is ethically significant because a failure to adequately assess the eligibility of a child for MAID may result in unjustified use or denial of MAID. The unjustified denial of MAID would entail a failure to fairly provide a medical intervention (i.e., MAID) to a child who experiences morally significant intolerable suffering like others who do receive this intervention. Alternatively, the unjustified use of MAID could entail the unjustified ending of a child's life through providing MAID due to an incorrect assessment of eligibility. Everyone is potentially vulnerable in the context of MAID, including adults $^{3}$; however, children are in a position of compounded vulnerability in this context due to their existing childhood-related vulnerabilities (e.g., being embedded in adult-privileging power dynamics, inability to defend oneself from risk of harm ${ }^{59}$ ). Given this compounded vulnerability and the irreversibility of death, it is essential to ensure that MAID is truly justified in each case of a minor. Therefore, uncertainty about a child's degree of suffering is especially concerning.

\section{Safeguards}

The risk of false determinations of eligibility for MAID is legally significant because the objective of the law is to protect persons from risks (e.g., risk of abuse and error) ${ }^{1}$. Acts like MAID for minors may be permitted despite the presence of these risks when appropriate safeguards are put in place to minimize the risks ${ }^{1}$. Given the risk of error associated with 
working through the complexity of children's voices in the context of MAID, it is important to consider possible legal safeguards.

A requirement by provincial and territorial governments to consider multiple factors in decision making pertaining to MAID for a minor, such as the child's medical situation, family dynamics, the emotional and physical impact of further medical interventions on the child, and availability and potential efficacy of further palliative care measures is one possible safeguard ${ }^{6}$.

Other potential safeguards entail using the very mediated nature of voice that contributes to its complexity as part of the solution. One possibility is a requirement for the involvement of a psychologist or psychiatrist in MAID discussions (as is the case in Belgium and the Netherlands $)^{6}$, not as a means of evaluating the child's voice for validity, authenticity, or worthiness of consideration, but as a means of helping work through some of the complexity of voice through dialogue with children. The involvement of a psychologist is in line with the existing inter-professional approach to pediatric healthcare ${ }^{6}$. When already integrated into the inter-professional healthcare team, psychologists and psychiatrists already have an intimate knowledge of the child's medical, psychosocial, and personal history ${ }^{6}$ which could help address some of the complexity of voice. Parental involvement can also be a similarly important safeguard when parents/guardians serve as interpretive interlocutors, using iterative dialogue with the child to facilitate a clearer understanding of the perspective a child is trying to express.

Substitute decision makers(often parents/guardians) for minors are obligated to make healthcare decisions in minors' best interests ${ }^{11}$. A decision is in the best interest of a child if it maximizes benefits and minimizes burdens for the child, and meets a standard of care that any ordinary, reasonable person would expect ${ }^{11}$. We believe that eliciting children's voices is a key component of this assessment, informing an understanding of benefits, burdens, and 
consequently, what is in an individual child's best interests. Given the importance of the best interests standard in decision-making in pediatric healthcare, it is not difficult to imagine that incorporation of the best interests standard is one way in which MAID for (non-mature) minors would differ from MAID for adults. Can MAID ever be linked to a child's best interests? It is unclear what a decision in the best interests of a child would look like in the context of MAID for (non-mature) minors. Possible use of the best interests standard as a supplemental protective safeguard ought to be considered, since it is required for all other healthcare decisions affecting non-mature minors.

\section{Conclusion}

Children's voices can provide meaningful insight into their illness and end-of-life experiences, such as the degree and extent of their suffering, thereby holding the potential to help determine their eligibility for MAID. If policy makers and legislators are to extend MAID legislation to minors in Canada, they need to carefully consider when and how to incorporate this information from children's voices. Policy makers and legislators need to engage in this careful consideration because the information from children's voices may not always be clear or certain enough to make it morally acceptable for use towards making decisions pertaining to MAID for a minor. Further, policy makers would have to deliberate about legal safeguards that could be put in place to mitigate the possible negative repercussions of operating under some level of uncertainty.

If legislators are to consider extending MAID legislation to most minors in Canada, they will need to exercise caution in determining if and how to implement the legislation. Exercising caution would entail carefully deliberating, perhaps through enlisting further independent reviews and communication with experts, about whether there may be too much uncertainty in 
individual instances of using the insights derived from children's voices to make decisions pertaining to MAID. If insights derived from children's voices are not considered to entail too much uncertainty to serve this specific epistemological purpose, there would be a need to consult with the appropriate experts to consider what degree of uncertainty is morally acceptable and how any legal risks of operating under some uncertainty could be mitigated.

\section{References}

1. Carter v. Canada (Attorney General), 2015 SCC 5, [2015] 1 S.C.R. 331. Available from: https://scc-csc.lexum.com/scc-csc/scc-csc/en/item/14637/index.do

2. Legislative Summary of Bill C-14: An Act to Amend the Criminal Code and make Related Amendments to other Acts (Medical Assistance in Dying) [Internet]. Ottawa (ON): Library of Parliament Research Publications, Parliament of Canada; [modified 2016 April]. Available from:

http://www.lop.parl.gc.ca/About/Parliament/LegislativeSummaries/ bills_1s.asp?Language $=$ E $\& 1 s=\mathrm{C} 14 \&$ Mode $=1 \&$ Parl=42\&Ses $=1 \&$ source=library_prb

3. Special Joint Committee on Physician Assisted Dying. Medical assistance in dying: A patient-centered approach. Report of the Special Joint Committee on Physician-Assisted Dying. Ottawa (ON): Parliament of Canada; 2016.

4. Kleinig, J. Consent. In: LaFollette H, editor. International Encyclopedia of Ethics. New Jersey: Blackwell Publishing Ltd; 2013.

5. Press release: Government of Canada initiates studies related to medical assistance in dying [Internet]. Ottawa (ON): Health Canada; 2016 December 13. Available from: https://www.canada.ca/en/health-canada/news/2016/12/government-canada-initiatesstudies-related-medical-assistance-dying.html 
6. Council of Canadian Academies, 2018. The State of Knowledge on Medical Assistance in Dying for Mature Minors. Ottawa (ON): The Expert Panel Working Group on MAID for Mature Minors, Council of Canadian Academies.

7. Beauchamp, T.L. The four principles approach to health care ethics. In: Beauchamp T.L., editor. Standing on principles: Collected essays. New York: Oxford University Press; 2010. p. 35-49.

8. Leo, R.J. Competency and the capacity to make treatment decisions: A primer for primary care physicians. Prim Care Companion J Clin Psychiatry. 1999;1(5): 131-41.

9. Health Care Consent Act, S.O. 1996, c 2, Sched. A. Available from: https://www.ontario.ca/laws/statute/96h02\#BK0

10. Infants Act, RSBC 1996, c 223. Available from: http://www.bclaws.ca/civix/document/id/complete/statreg/96223_01\#section17

11. Coughlin, K.W.; Canadian Pediatric Society, Bioethics Committee. Medical decisionmaking in paediatrics: Infancy to adolescence. Paediatr Child Health. 2018;23(2): 13846.

12. Article 12 of the Convention on the Rights of the Child and Children's Participatory Rights in Canada [Internet]. Ottawa (ON): Department of Justice, Government of Canada; [modified 2017 January]. Available from: http://www.justice.gc.ca/eng/rp-pr/otherautre/article12/p3a.html

13. Driggs, A.E. The mature minor doctrine: Do adolescents have the right to die? Health Matrix. 2001;11(2): 687-717.

14. A.C. v. Manitoba (Director of Child and Family Services), 2009 SCC 30, [2009] 2 S.C.R. 181. Available from: https://scc-csc.lexum.com/scc-csc/scc-csc/en/item/7795/index.do 
15. Prout, A. Participation, policy, and the changing conditions of childhood. In: Hallet C, Prout A, editors. Hearing the voices of children: Social policy for a new century. New York: Routledge Falmer; 2003. p.11-25.

16. Uprichard, E. Children as "being and becomings:" Children, childhood and temporality. Child Soc.2018;22(4): 303-13.

17. Arneil, B. Becoming versus being: A critical analysis of the child in liberal theory. In: Archard D, Macleod CM, editors. The moral and political status of children. New York: Oxford University Press; 2002. p. 70-96.

18. James, A., and A. Prout. A new paradigm for the sociology of childhood?: Provenance, promise, and problems. In: Constructing and reconstructing childhood: Contemporary issues in the sociological study of childhood. Abingdon: Routledge; 2015. p. 6-28.

19. Carnevale, F.A. Listening authentically to youthful voices: A conception of the moral agency of children. In: Rodney SP, Starzomski S, editors. Toward a moral horizon: Nursing ethics for leadership and practice (2nd ed). Toronto: Pearson Education Canada; 2012. p. 315-32.

20. Nussbaum, M.C. Chapter 8: Objectification. In: Sex and social justice. New York: Oxford University Press; 1999. p. 213-39.

21. Warren, M.A. Personhood and moral rights. In: Harris J, Holm S, editors. Moral status: Obligations to persons and other living things. New York: Oxford University Press; 1997. p. $90-121$.

22. Graf, G. Conceptions of childhood, agency, and the well-being of children. In: Graf G, Schweiger G, editors. The well-being of children: Philosophical and social scientific approaches 1st ed. Berlin: De Gruyter; 2015, p. 20-33. 
23. Montreuil, M., and F.A. Carnevale. A concept analysis of children's agency within the health literature. J Child Health Care. 2016;20(4): 503-11.

24. Carnevale, F.A., A. Campbell, D. Collin-Vézina, and M.E. Macdonald. Interdisciplinary studies of childhood ethics: Developing a new field of inquiry. Child Soc. 2015;29(6): 511-23.

25. James, A. Giving voice to children's voices: Practices and problems, pitfalls and potentials. Am Anthropol. 2007;109(2): 261-72.

26. Carnevale, F.A., Alexander, E., Davis, M., J. Rennick, and Troini, R. Daily living with distress and enrichment: The moral experience of families with ventilator-assisted children at home. Pediatrics. 2006;117(1): e48-60.

27. Terry, L., and A. Campbell. Focus on children's nursing. Are we listening to children's views about their treatment? Br J Nurs. 2001;10(6): 384-90.

28. Lewis, A. Silence in the context of 'child voice'. Child Soc. 2010;24(1): 14-23.

29. Spyrou, S. Researching children's silences: Exploring the fullness of voice in childhood research. Childhood. 2016;23(1): 7-21.

30. Teachman, G., P. McDonough, C. Macarthur, and B.E. Gibson. A critical dialogical methodology for conducting research with disabled youth who use augmentative and alternative communication. Qual Inq. 2017;24(1): 35-44.

31. Smart, C. From children's shoes to children's voices. Fam Ct Rev. 2002;40(3): 307-19.

32. Carter, B. Chronic pain in childhood and the medical encounter: Professional ventriloquism and hidden voices. Qual Health Res. 2002;12(1): 28-41.

33. George, R. T. D. The function and limits of epistemic authority. South J Philos. 1970;8(2-3): 199-204. 
34. Davidson, D. First person authority. Dialectica. 1984;38(2-3): 101-11.

35. Burton S., and P. Mitchell. Judging who knows best about yourself: Developmental change in citing the self across middle childhood. Child Dev. 2003;74(2): 426-443.

36. Bennett, M., P. Mitchell, and P. Murray. Children's judgements about their own self knowledge: The role of disclosure to other. Brit J Dev Psychol. 2010;27(3): 731-742.

37. Falvey, K. The basis of first-person authority. Philos Topics. 2000;28(2): 69-99.

38. Tates Kiek, K. Doctor-parent-child relationships: a 'pas de trois'. Patient Educ Couns. 2003;48(1): 5-14.

39. Kars, M. C., M.H.F. Grypdonck, L.C. de Bock, and J.J.M. van Delden. The parents' ability to attend to the "voice of their child" with incurable cancer during the palliative phase. Health Psychol. 2015;34(4): 446-52.

40. Carter, B. S. Why palliative care for children is preferable to euthanasia. Am J Hosp Palliat Med. 2016;33(1): 5-7.

41. Singh HK. Medical Assistance in Dying (MAID) for Minors in Canada: Considering Children's Voices [master's thesis]. [Montreal]: McGill University; 2018. 84 p.

42. Bitou, A., and T. Waller. Researching the rights of children under three years old to participate in the curriculum in early years education and care. In: Harcourt D, Perry B, Waller T, editors. Researching young children's perspectives: Debating the ethics and dilemmas of educational research with research. New York: Routledge; 2011. p. 53-67.

43. Gottlieb, A. Where have all the babies gone? Toward an anthropology of infants (and their caretakers). Anthropol Quart. 2000;73(3): 121-32.

44. Smorholm, S. Pure as the angels, wise as the dead: Perceptions of infants' agency in a Zambian community. Childhood. 2016;23(3): 348-61. 
45. Hart, S.N. Making sure the child's voice is heard. Int Rev Educ. 2002;48(3-4): 251-58.

46. Council of Canadian Academies, 2018. The State of Knowledge on Medical Assistance in Dying where a Mental Disorder Is the Sole Underlying Medical Condition. Ottawa (ON): The Expert Panel Working Group on MAID Where a Mental Disorder Is the Sole Underlying Medical Condition.

47. Wijsbek, H. The subjectivity of suffering and the normativity of unbearableness. In: Kimsma GK, Youngner SJ, editors. Physician-assisted death in perspective: Assessing the Dutch experience. Cambridge: Cambridge University Press; 2012. p. 319-32.

48. Guichon, J., F. Mohamed, K. Clarke, and I. Mitchell. Autonomy and beneficence in assisted dying in Canada: The eligibility of mature minors. Alta L Rev. 2017;54(3): 775-831.

49. Mazzei, L.A. An impossibly full voice. In: Jackson AY, Mazzei LA, editors. Voice in qualitative inquiry: Challenging conventional, interpretive, and critical conceptions in qualitative research. New York: Routledge; 2009. p. 45-62.

50. Spyrou, S. The limits of children's voices: From authenticity to critical, reflexive representation. Childhood. 2011;18(2): 151-65.

51. Wyness, M. Children's participation and intergenerational dialogue: Bringing adults back into the analysis. Childhood. 2013;20(4): 429-42.

52. Komulainen, S. The ambiguity of the child's 'voice' in social research. Childhood. 2007;14(1): 11-28.

53. Meloni, F., K. Vanthuyne, and C. Rousseau. Towards a relational ethics: Rethinking ethics, agency and dependency in research with children and youth. Anthropol Theor. 2015;15(1): 106-23. 
54. Mackenzie, C., and N. Stoljar. Introduction: Autonomy refigured. In: Mackenzie C, Stoljar N, editors. Relational autonomy: Feminist perspectives on autonomy, agency, and the social self. New York: Oxford University Press; 2000. p. 3-31.

55. McLeod, C., and S. Sherwin. Relational autonomy, self-trust, and health care for patients who are oppressed. In: Mackenzie C, Stoljar N, editors. Relational autonomy: Feminist perspectives on autonomy, agency, and the social self. New York: Oxford University Press; 2000. p. 259-79.

56. Carnevale, F.A., G. Teachman, and A. Bogossian. A relational ethics framework for advancing practice with children with complex health care needs and their parents. Compr Child Adolesc Nurs. 2017;40(4): 268-84.

57. Position statement: Medical assistance in dying: A paediatric perspective [Internet]. Canadian Paediatric Society, Bioethics Committee; [modified 2018 April]. Available from: https://www.cps.ca/en/documents/position/medical-assistance-in-dying

58. Canadian Charter of Rights and Freedoms, Part I of the Constitution Act, 1982, being Schedule B to the Canada Act 1982 (UK), 1982, c11

59. Hurst, S. Clarifying vulnerability: The case of children. Asian Bioeth Rev. 2015;7(2): 126138. 